Review article

2021 | Volume 9 | Issue 1 | Pages 19-23

ARTICLE INFO

Received

January 14, 2021

Revised

March 11, 2021

Accepted

March 15, 2021

Published

April 16, 2021

*Corresponding authors

Baseer Ahmad

E-mail

dr.baseerahmadkhan@gmail.com

Keywords

Avian influenza

Backyard poultry

Biosecurity risk

H9N2 subtype

Rural people

How to cite

Khan M, Chaudhry M, Fatima

Z, Khan RU, Ahmad B, Ullah

R, Khan A. Effect of avian

influenza H9N2 subtype virus

infection on backyard poultry production. Sci Lett 2021;

9(1):19-23
Open Access

\section{Effect of Avian Influenza H9N2 Subtype Virus Infection on Backyard Poultry Production}

Mirwaise Khan¹, Mamoona Chaudhry², Zeeshan Fatima², Rahat Ullah Khan ${ }^{3}$, Baseer Ahmad ${ }^{4 *}$, Rahman Ullah ${ }^{5}$, Aimal Khan ${ }^{6}$

${ }^{1}$ Department of Epidemiology and Public Health, Faculty of Veterinary and Animal Sciences, Gomal University, Dera Ismail Khan, Khyber Pakhtunkhwa, Pakistan

${ }^{2}$ Disease Surveillance Laboratory, Department of Epidemiology and Public Health, University of Veterinary and Animal Sciences, Lahore, Pakistan

${ }^{3}$ Institute of Microbiology, Gomal University, Dera Ismail Khan, Khyber Pakhtunkhwa, Pakistan

${ }^{4}$ Department of Animal Nutrition, Faculty of Veterinary and Animal Sciences, Gomal University, Dera Ismail Khan, Khyber Pakhtunkhwa, Pakistan

${ }^{5}$ Department of Dairy Technology, Faculty of Veterinary and Animal Sciences, Gomal University, Dera Ismail Khan, Khyber Pakhtunkhwa, Pakistan

${ }^{6}$ Livestock and Dairy Development Department, Balochistan, Pakistan

\section{Abstract}

Avian influenza is a viral pandemic disease of humans and birds, including commercial and house poultry. Avian influenza is a major concern around the world, which causes serious economic losses in the poultry industry, mainly in home backyard poultry. The backyard poultry is the potential source of income for rural people and indirectly contributes to decreasing the poverty of household women. Besides, in many developing countries, villagers full fill a part of their food demand by the backyard poultry; however, this sector is directly affected by biosecurity risks, including high and low pathogenic avian influenza infections like avian influenza H9N2 subtype. Avian influenza H9N2 subtype has low pathogenic zoonotic importance but still causes serious threats to the poultry industry. The backyard poultry industry is directly affected by this infection due to direct contact with wild migratory birds locating in different regions of the world. Antigenic drift and shift are one of the major conflicts of this infection resulting from a few days to a few months up to many years and also the main reason for the uncontrollable mutation in this infection. All over the world, there is no serious action taken to prevent the H9N2 subtype infection in backyard poultry. This situation has become severe because of the widespread of highly pathogenic avian influenza viruses in the past few years. 


\section{Introduction}

Influenza is an acute disease in poultry as well as in humans. Viruses of influenza have negativesense RNA genomes and are placed in the Orthomyxoviridae family. The grouping of viruses is based on matrix protein namely as A B and C [1]. Influenza causes pandemics in humans and affects various kinds of species, including chicken, pigs, whales, ducks, horses, etc. [1]. Severe economic losses have resulted from different avian influenza virus subtypes (including $\mathrm{H} 5 \mathrm{~N} 1$ and $\mathrm{H} 9 \mathrm{~N} 2$ ), but backyard poultry is beyond simple calculation. All over the globe, mass vaccination was done in commercial poultry farming to inhibit the number of avian influenza cases but no proper preventive measurements were taken in the backyard poultry sector. Usually, in case of a large number of cases, the use of vaccination causes increased refusal, including resistance to the virus but also prevents illness which reduces the death rate with a decline in environmental contamination [1]. In Korea, H9 avian influenza viruses isolated from 2002 to 2004 continuously evolved of antigenic drift having under the review of reassortment with aquatic and influenza type A virus [3]. At the time of the first avian influenza virus outbreak in Korea, five H9N2 viruses were isolated from several different broiler breeder flocks in Korea. Most of the affected birds showed typical signs of influenza, including an unstable drop in egg production in mortality, alarming with the passage of different intervals of time [3]. There is increasing evidence that H9N2 avian influenza viruses are endemic in domestic and industrial chickens and other populations of poultry (such as chukar, quail, pheasant, etc.) in many Asian and European countries [4]. In many Asian countries, backyard as well as commercial poultry farming plays a major role to provide a sufficient percentage of protein in the form of meat and eggs. Increasing the population day by day will directly enhance the food requirement percentage items all around the globe. So, this source has become a potent source of energy between the supply and requirement of animal protein. Rural poultry has made a significant contribution to the alleviation of poverty in many developed and underdeveloped countries [5]. H9N2 virus affects all sectors of the poultry population, including commercial poultry and backyard poultry, and the risk factor of the infection spread increases with wild migratory birds, which have no limitations of traveling by crossing the international boundaries easily [5]. Besides, the unawareness of farmers and lack of knowledge of the systematic source of this infection also play an important role in the spreading of infection [7]. In the backyard poultry production system, women contribute an important role in the development of this sector to full fill their economic needs on a routine basis by rearing birds at homes [8]. In underdeveloped countries, the families keep backyard poultry up to a small flock ranging from 2-10 chickens and mostly women manage feeding for these birds [9]. Here, we tried to elaborate epidemiology, life cycle, identification method and risk-scale of avian influenza to backyard poultry. Further, we suggest some future actions and guidelines to reduce the risk of avian influenza for backyard poultry.

\section{Epidemiology and life cycle of avian influenza virus}

Influenza is a viral infectious disease that occurs worldwide in humans, as well as in commercial poultry. The majority of human infections have resulted from type A and B. However, avian influenza infections were noted widespread around the world with two subtypes in the premises of poultry. H9N2 infection, which is an LPAI infection, was spread around 1990 in the whole of Asia. The epidemiological study suggests that poultry was the source of infection in the outbreak of 1997 in humans [10]. Viruses require living cell sites for their replication. Influenza virus replication and infection initiation is a multistep process. Firstly, the virus may bind for entering into the cell. After the entrance, virus delivers its genome to the site where it can produce new copies of viral proteins and RNA. Through hemagglutinin, the virus binds onto sialic acid sugars on epithelial cell surfaces typically in the intestine of birds, nose throat, and lungs of mammals. The incubation period of avian influenza comprises of 48 hours to 4 days. In humans, alpha-2, 3-linkages with sialic acids are found in the respiratory epithelium, though in less amount than those with alpha-2, 6linkages $[11,12]$.

\section{Identification of Virus}

Many diagnostic tests are available for the detection of influenza viruses in respiratory specimens, including molecular assays (rapid molecular assays, reverse transcription-polymerase chain reaction-RT-PCR and other nucleic acid 
amplification tests) and antigen detection tests (rapid influenza diagnostic tests). Serological testing for influenza is offered by some commercial laboratories, which test for antibodies to influenza A or B viruses. For analysis, a single serum specimen cannot be reliably interpreted. So, proper serological testing for the diagnosis of influenza requires paired acute and convalescent sera collected 2-3 weeks apart to assess a 4-fold or greater rise in influenza virus strain-specific antibodies. Rapid influenza diagnostic tests (RIDTs) are antigen detection assays that can detect influenza viral antigens in 10-15 minutes with moderate sensitivity (50-70\%) and high specificity [13].

\section{Influence of avian influenza virus on backyard poultry production}

Small scale poultry is reared by the household's family labor using locally available mixed feed resources in developing countries. Usually, in a backyard poultry rearing system, there is much more movement of backyard chickens inside or outside the home and scavenge and share most of their food with other wild birds [14]. Almost all rural and urban families keep a small number of flocks of usually 5-20 adult chickens, mostly managed by women and children. Profits are normally low, and products are used for home consumption or given as gifts or offered for religious purposes $[15,16]$. An increase in the chance of airborne transfer of avian influenza may occur if village poultry is close to commercial layer operation or housed on the farm. Similarly, avian influenza directly affects all sectors of poultry in most Asian countries, but its presence seems high in commercial ducks, village poultry, live bird markets, and fighting cocks [17-19]. The majority of infections in between the backyard and other commercial and wild migratory birds play a role in increasing the prevalence of the $\mathrm{H} 9$ subtype virus around the globe. Around the globe, wild migratory birds have become the potent source of infection because those normally carry the infection of avian influenza in their respiratory and intestinal tracts and don't get sick as a reservoir host for this virus. A close surveillance system is needed to be introduced to monitor the occurrence and characteristics of avian influenza viruses in wild migratory birds. However, the presence of water around backyard poultry is considered the lowest possibility as a model for the introduction of avian influenza viruses from village poultry to commercial poultry [20].

Backyard poultry is defined as freely roam birds in a confined area with humans and animals. These backyard birds can also scavenge different types of feeding with wild migratory birds that become a potent source of H9N2 infection [21]. In recent years, the avian influenza H9N2 virus caused severe economic losses in the rural poultry sector [22]. The village chicken is a very important asset in many developing countries and plays a vital role to full fill the requirement of protein in the form of meat and eggs. Rearing of backyard poultry is not only a hobby activity but it is also the source of protein diet for poor households. This production sector is one of the major contributors in developed and underdeveloped countries to decline the poverty line at some expected level. Due to the low adjustable cost and rapid turnover of fruitful production, women and children rear chicken in a very confined area of the home. In Bangladesh, a survey was conducted from January 2002 to March 2006, which reported a seroprevalence of avian influenza virus of $23 \%$ in flocks and $20 \%$ in chickens [23]. In another study conducted in backyard chickens around the Maharlou Lake in Iran in 2011, the seroprevalence of $\mathrm{H} 9 \mathrm{~N} 2$ was $81.6 \%$, higher than the $\mathrm{H} 9$ seroprevalence reported in the above-cited study [24]. The $3^{\text {rd }}$ study of Vietnam was conducted to demonstrate the status of $\mathrm{H} 5 \mathrm{~N} 1$ in backyard poultry and smallholder commercial duck farms and reported the bird-level seroprevalence of $\mathrm{H} 5$ to be $17.5 \%$ [25]. Another study was conducted in Bangladesh where the $9.8 \%$ overall seroprevalence was recorded [26]. This was the minimum seroprevalence among the above-cited studies. It also includes that in the case of backyard poultry production system, a high mortality rate is common. In Thailand, a study was conducted with its first objective to determine the prevalence of avian influenza occurrence in backyard chickens. Antibody positivity found in this study with the methodology of HA and HI was assumed to be the proof of avian influenza virus infection in backyard chickens in which the calculated prevalence was obtained from a total of 8 districts out of 87 study districts. The prevalence calculated was relatively low in less than 2 birds out of a total of 100 birds $(1.5 \%)$ [27]. Yendell et al. found very low seroprevalence $(0.7 \%)$ of avian influenza infection in backyard chickens having less or no contact with migratory birds [28]. In contrast, a 2006 New 
Zealand study targeting chicken flocks with known wild waterfowl exposure found $20.8 \%$ seropositive birds [29]. Active surveillance study of avian influenza in northern Italy from 2004-2006 found 27 low pathogenic avian influenza viruses isolated from backyard poultry, including 49 strains obtained from wild birds [30]. Chaudhry et al. conducted a matched control study with the main objective to identify H9N2 subtype virus infection based on their different potential risk factors in different commercial poultry farms of Punjab Province of Pakistan to help the poultry production systems [31]. In a serological study, Kausar et al. collected samples from various non-vaccinated bird species suspected for an avian influenza virus infection and among those, rural poultry (6\%), domestic desi birds (5\%) and desi chicken (3.6\%) were reported positive by using HI test protocol [32]. Correspondingly, backyard poultry is a potent source of avian influenza infection in this farming system, primarily because these birds are mostly free-range. The availability of feed attracts the wild migratory birds towards the direction of backyard poultry.

\section{Conclusions}

Different serological prevalence's observed in this review, including studies from different regions indicate that H9N2 infection is endemic in backyard chickens all around the world. The main objective of this review is to provide accurate estimates of the seroprevalence of avian influenza virus $\mathrm{H} 9$ subtype in backyard poultry to identify high-risk areas or villages for the future surveillance and progressive control of avian influenza virus in hotspot areas and to characterize the backyard production system in the future. The presence of antibodies to $\mathrm{H} 9$ in every above-cited study confirmed the exposure of chickens to circulating avian influenza viruses. A gross route level vaccination strategy is needed for the control of H9N2 infection in the backyard poultry to prevent the first phase of infection to reduce the risk of spread of avian influenza. Besides, continuous surveillance of backyard poultry would be needed because these birds are at higher risk of contracting infection due to the free-range systems having no international boundary restriction. However, it's to be needed to control the endemicity of H9N2 infection up to $20 \%$ despite not being exceeded this percentage, causing severe economic losses in the dimension of secondary infection resulting from respiratory disturbances which directly altered the egg production of backyard birds. Control of infection in human is to be necessary by washing their hands after handling birds, including backyard and other fancy birds which probably decrease the prevalence of infection among them. Increasing the surveillance system will help to better define the seasonal pattern in the circulation of avian influenza H9N2 subtype as well as to determine the optimal period of infection and to decrease the percentage of prevalence among backyard poultry.

\section{Conflict of interest}

The authors declare no conflict of interest.

\section{References}

[1] Alexander DJ. A review of avian influenza in different bird species. Vet Microbiol 2000;74(1-2):3-13.

[2] Mo I, Song C, Kim K, Rhee J. An occurrence of nonhighly pathogenic avian influenza in Korea. Avian dis 2003; 47:379-383.

[3] Peyre M, Fusheng G, Desvaux S, Roger F. Avian influenza vaccines: a practical review in relation to their application in the field with a focus on the Asian experience. Epidimol Infect 2009; 137(1):1-21.

[4] Guan Y, Short KF, Krauss S, Webster RG. Molecular characterization of H9N2 influenza viruses: were they the donors of the "internal" genes of H5N1 viruses in Hong Kong. Proc Natl Acad Sci USA 1999; 96:93639367.

[5] Sharif A, Siddique N, Abbas MA, Rafique S, Farooq S, Nawaz R. Surveillance of low pathogenic Avian influenza virus among non-vaccinated birds in Pakistan. Biomed Lett 2019; 5(1):33-40.

[6] Sims LD, Domenech J, Benigno C, Kahn S, Kamata A, Lubroth J, Martin V, Roeder P. Origin and evolution of highly pathogenic H5N1 avian influenza in Asia. Vet Rec 2005; 157(6):159-164.

[7] Iqbal M. Controlling avian influenza infections: The challenge of the backyard poultry. J Mol Genet Med 2009; 3(1):119-120.

[8] Capua I, Alexander DJ. Human health implications of avian influenza viruses and paramyxo viruses. Eur J Clin Microbial Infect Dis 2004; 23(1):1-6.

[9] Sonaiya EB, Swan SE Small-scale poultry production: Technical guide, F.A.O. 2004; http://www.smallstock.info/reference/FAO/008/y516 $9 \mathrm{e} / \mathrm{y} 5169 \mathrm{e} 00$.

[10] Chan PK. Outbreak of avian influenza A(H5N1) virus infection in Hong Kong in 1997. Clin Infect Dis 2002; 34:58-64.

[11] Couceiro JN, Paulson JC, Baum LG. Influenza virus strains selectively recognize sialyl oligosaccharides on human respiratory epithelium; the role of the host cell in selection of hemagglutinin receptor specificity. Virus Res 1993; 29(2):155-165.

[12] Matrosovich MN, Matrosovich TY, Gray T, Roberts NA, Klenk HD. Human and avian influenza viruses 
target different cell types in cultures of human airway epithelium. Proc Natl Acad Sci USA 2004; 101(13):4620-4624.

[13] Kim D-K, Poudel B. Tools to detect influenza virus. Yonsei medical journal 2013; 54(3):560.

[14] Sonaiya EB. International network for family poultry development: Origins, activities, objectives and visions. In Poultry as a Tool in Poverty Eradication and Promotion of Gender Equality Proceedings of a workshop; 1999.

[15] Permin A, Pedersen G. The need for a holistic view on disease problems in free-range chickens. Network for Smallholder Poultry Development, The Royal Veterinary and Agricultural University Frederiksberg, Denmark; 2002.

[16] Riise JC, Permin A, McAinsh CV, Frederiksen L. Keeping village poultry: a technical manual on smallscale poultry production; 2005.

[17] Martin V, Sims L, Lubroth J, Kahn S, Domenech J, Begnino C. History and evolution of HPAI viruses in south east Asia. Ann NY Acad Sci 2006; 1081(1):153162.

[18] Sims L. Experience in control of avian influenza in Asia. Developments in biological 2006; 130:39-43.

[19] Songserm T, Jam-on R, Sae-Heng N, Meemak N, Hulse-Post DJ, Sturm-Ramirez KM, Webster RG. Domestic ducks and H5N1 influenza epidemic, Thailand. Emerg Infec Dis 2006; 12(4):575.

[20] Sims LD, Weaver J, Swayne DE. Epidemiology of avian influenza in agricultural and other man-made systems. In: Animal Influenza, 2016; pp. 59-85.

[21] Permin A, Pedersen G. The need for a holistic view on disease problems in free range chickens, characteristics and parameters of family production system in Africa. Vienna, Inter. Atomic Energy Agency, 2002; pp. 9-13.

[22] Abbas MA, Spackman E, Swayne DE, Ahmed Z, Sarmento L, Siddique $N$, et al. Sequence and phylogenetic analysis of H7N3 avian influenza viruses isolated from poultry in Pakistan 1995-2004. Virol J 2010; 7(1):137.

[23] Biswas PK, Barua H, Uddin GM, Biswas D, Ahad A, Debnath NC. Serosurvey of five viruses in chickens on smallholdings in Bangladesh. Prev Vet Med 2009; 88(1):67-71.
[24] Hadipour MM, Habibi G, Vosoughi A. Prevalence of antibodies to H9N2 avian influenza virus in backyard chicken around Maharlou lake in Iran. Pak Vet J 2011; 31(3):192-194.

[25] Henning J, Henning KA, Morton JM, Long NT, Ha NT. Vu LT, et al. Highly pathogenic avian influenza (H5N1) in ducks and in-contact chickens in backyard and smallholder commercial duck farms in Viet Nam. Prev Vet Med 2011; 101(3-4):229-240.

[26] Nooruddin GM, Hossain MT, Mohammad M, Rahman MM. Sero-epidemiology of avian influenza virus in native chicken in Bangladesh. Int J Poult Sci 5:10291033.

[27] Chantong W. Epidemiological study of avian influenza in backyard chickens and open field-reared ducks in Northern Thailand. Dissertation, Michigan State University. Large Animal Clinical Sciences; 2011.

[28] Yendell S, Rubinoff I, Lauer D, Bender J, Scheftel J. Antibody prevalence of low pathogenicity avian influenza and evaluation of management practices in minnesota backyard poultry flocks. Zoonoses Public Health 2012; 59(2):139-143.

[29] Zheng T, Adlam B, Rawdon T, Stanislawek W, Cork S, Hope V, et al. A cross-sectional survey of influenza A infection, and management practices in small rural backyard poultry flocks in two regions of New Zealand. New Zealand Vet J 2010; 58(2):74-80.

[30] Terregino CR, De Nardi V, Guberti M, Scremin E, Raffini A, Martin M, et al. Active surveillance for avian Influenza viruses in wild birds and backyard flocks in Northern Italy during 2004 to 2006. Avian Pathol 2007; 36(4):337-344.

[31] Chaudhry M, Rashid HB, Thrusfield M, Welburn S, Bronsvoort BM. A case control study to identify risk factors associated with avian influenza subtype H9N2 on commercial poultry farms in Pakistan. PloS one 2015; 10(3): e0119019.

[32] Kausar A, Anwar S, Siddique N, Ahmed S, Dasti JL. Prevalence of avian influenza H9N2 virus among wild and domesticated bird species across Pakistan. Pak J Zoo 2018; 50(4):1347-1347. 